\title{
Magnetic composites based on metallic nickel and molybdenum carbide: A potential material for pollutants removal
}

\author{
Raquel V. Mambrini ${ }^{a}$, Thales L. Fonseca ${ }^{a}$, Anderson Dias $^{b}$, Luiz C.A. Oliveira $^{a}$, Maria Helena Araujo ${ }^{a}$, \\ Flávia C.C. Moura ${ }^{\mathrm{a}, *}$ \\ a Departamento de Química, Universidade Federal de Minas Gerais, Belo Horizonte, MG 31270-901, Brazil \\ b Departamento de Química, Universidade Federal de Ouro Preto, Ouro Preto, MG 35400-000, Brazil
}

\section{H I G H L I G H T S}

- New magnetic molybdenum carbide composites can be prepared by CVD from ethanol.

- Magnetic molybdenum carbide shows promising results for pollutants removal.

- The carbide composites can be easily recovered magnetically and reused.

\section{A R T I C L E I N F O}

\section{Article history:}

Received 14 May 2012

Received in revised form 15 August 2012

Accepted 2 September 2012

Available online 7 September 2012

\section{Keywords:}

Carbides

Magnetic materials

Vapor deposition

Sulfur and nitrogen removal

\begin{abstract}
A B S T R A C T
New magnetic composites based on metallic nickel and molybdenum carbide, $\mathrm{Ni} / \mathrm{Mo}_{2} \mathrm{C}$, have been produced via catalytic chemical vapor deposition from ethanol. Scanning electron microscopy, thermal analysis, Raman spectroscopy and X-ray diffraction studies suggest that the CVD process occurs in a single step. This process involves the reduction of NiMo oxides at different temperatures $(700,800$ and $900^{\circ} \mathrm{C}$ ) with catalytic deposition of carbon from ethanol producing molybdenum carbide on Ni surface. In the absence of molybdenum the formation of $\mathrm{Ni} / \mathrm{C}$ was observed. The magnetic molybdenum carbide was successfully used as pollutants removal by adsorption of sulfur and nitrogen compounds from liquid fuels and model dyes such as methylene blue and indigo carmine. The dibenzothiofene adsorption process over $\mathrm{Ni} / \mathrm{Mo}_{2} \mathrm{C}$ reached approximately $20 \mathrm{mg} \mathrm{g}^{-1}$, notably higher than other materials described in the literature and also removed almost all methylene blue dye. The great advantage of these carbide composites is that they may be easily recovered magnetically and reused.
\end{abstract}

(c) 2012 Elsevier B.V. All rights reserved.

\section{Introduction}

Transition metal carbides have been widely investigated in recent years because of their good catalytic activity and selectivity for hydrogenation, hydrodesulfurization and hydrodenitrogenation reactions in petroleum refining [1]. Among them molybdenum carbide has been extensively studied due to its unique physical and chemical properties including mechanical hardness, thermal stability, superconductivity and surface reactivity. Also, it has been reported that it possesses catalytic behavior comparable to noble metals [2-4]. The synthesis of $\mathrm{Mo}_{2} \mathrm{C}$ is typically carried out using Temperature Programmed Reaction (TPRe) where molybdenum oxide is heated under an atmosphere of hydrogen/hydrocarbon (e.g. $\mathrm{CH}_{4}, \mathrm{C}_{2} \mathrm{H}_{6}, \mathrm{C}_{2} \mathrm{H}_{2}$, etc.) [5-7]. Herein we report the preparation of the

\footnotetext{
* Corresponding author. Tel.: +55 31 34097556; fax: +55 3134095700 .

E-mail address: flaviamoura@ufmg.br (F.C.C. Moura).
}

magnetic composite $\mathrm{Ni} / \mathrm{Mo}_{2} \mathrm{C}$ via chemical vapor deposition (CVD) using ethanol as the carbon source.

Magnetic particles have many potential technological applications, e.g. support for catalysts [8,9], magnetic resonance imaging $[10,11]$, drug delivery [12], adsorption processes [13,14] and environmental remediation [8,15-17]. Magnetic particles can be coated with a protective layer of different materials to improve their stability and to introduce new surface properties and functionalities. Some of these coating materials are silica [18], alumina [19], gold [20], and polymers, such as polystyrene [21], polyaniline [22], polymethyl methacrylate [23] and polyacrylamide [24]. Carbon is a versatile coating material due to its chemical stability, biocompatibility, possibility of surface modification and pore creation [25], and have been used as efficient adsorbent in different applications.

The use of commercial fuels and the emissions from refineries are of great environmental impact and are among the main targets of the new environmental standards that suggests the reduction of sulfur and nitrogen in fuels like gasoline and oil diesel. The removal of these compounds is a major operation in petroleum refining and 
is achieved by catalytic processes operated at high pressures and temperatures $[24,25]$. The developed of new materials capable of lowering these reaction conditions have been intensively investigated [26].

In this work we describe the preparation and characterization of new magnetic composites based on metallic nickel and molybdenum carbide covered with carbon and their use as adsorbent of sulfur and nitrogen compounds using as model molecules dibenzotiophene and quinoline. The adsorption of organic dyes has also been investigated.

Transition metal carbides are considered as the new promising catalysts and have been widely investigated in recent years because of their good catalytic activity and selectivity in hydrogenation, hydrodesulfurization, and hydrodenitrogenation in petroleum refining [1].

Molybdenum carbide has been extensively studied due to its unique physical and chemical properties including mechanical hardness, thermal stability, superconductivity, and surface reactivity. Also, it is reported that molybdenum carbide possesses catalytic behavior comparable to the noble metals [2-4].

The synthesis of molybdenum carbide is typically carried out using Temperature Programmed Reaction (TPRe) where a given amount of the molybdenum oxide is heated while it is exposed to a mixture of hydrogen with a hydrocarbon like $\mathrm{CH}_{4}, \mathrm{C}_{2} \mathrm{H}_{6}, \mathrm{C}_{2} \mathrm{H}_{2}$, etc. [5-7]. Herein we report the production of molybdenum carbide covering the surface of $\mathrm{Ni}^{0}$ metallic. The magnetic composite $\mathrm{Ni} / \mathrm{Mo}_{2} \mathrm{C}$ was obtained by chemical vapor deposition (CVD) using ethanol as carbon source. Magnetic particles have many potential technological applications in different areas, such as in catalysis as support $[8,9]$, in biomedicine as magnetic resonance imaging $[10,11]$ in drug delivery, in adsorption process $[13,14]$ and in environmental remediation [8,15-17]. Magnetic particles can be coated with a protective layer of different materials to improve their stability and to introduce new surface properties and functionalities. Some of these coating materials are silica [18], alumina [19], gold [20], and polymers, such as polystyrene [21], polyaniline [22], polymethyl methacrylate [23] and polyacrylamide [24]. Carbon is a versatile coating material due to its chemical stability, biocompatibility, possibility of surface modification and pore creation [25], and have been used as efficient adsorbent in different applications.

The use of commercial fuels and the emissions from refineries are of great environmental impact and are among the main targets of the new environmental standards that suggest the reduction of sulfur and nitrogen in fuels like gasoline and oil diesel. The removal of these compounds is a major operation in petroleum refining and is achieved by catalytic processes operated at high pressures and temperatures $[26,27]$. Therefore research has been developed for new material capable of lowering the conditions reactions to removal of sulfur compounds and nitrogen compounds [28].

The study of magnetic particles coated with carbon for sulfur and nitrogen removal is of great interest. In this work the produced magnetic molybdenum carbide was used as an adsorbent of sulfur and nitrogen compounds using model molecules dibenzotiophene and quinoline and also has been used as organic dyes adsorbent.

\section{Experimental}

Commercially available solvents and reagents of high purity were used as received. Nickel oxide, $\mathrm{NiO}$, was obtained by heating $2 \mathrm{~g}$ of nickel chloride, $\mathrm{NiCl}_{2}$, (Synth) in air $10^{\circ} \mathrm{C} \mathrm{min}^{-1}$ up to $450{ }^{\circ} \mathrm{C}$ during $4 \mathrm{~h}$. $\mathrm{NiO}$ was impregnated with $\left(\mathrm{NH}_{4}\right)_{6} \mathrm{Mo}_{7} \mathrm{O}_{24} \cdot 4 \mathrm{H}_{2} \mathrm{O}$ (RioLab) at different Ni:Mo molar ratios to produce NiMo oxides. For the preparation of $\mathrm{Ni} / \mathrm{C}$ or $\mathrm{Ni} / \mathrm{Mo}_{2} \mathrm{C}$ a chemical vapor deposition (CVD) reaction using ethanol (Synth) as carbon source was investigated. About $500 \mathrm{mg}$ of $\mathrm{NiO}$ or $\mathrm{Ni} / \mathrm{Mo}$ oxides in a quartz tube of $30 \mathrm{~mm}$ diameter was placed in the central part of the oven and heated at $10^{\circ} \mathrm{Cmin}^{-1}$ up to 700,800 and $900^{\circ} \mathrm{C}$, and then a CVD process was carried out using ethanol $\left(80 \mathrm{~mL} \mathrm{~min}^{-1}\right)$ in $\mathrm{N}_{2}$ for $1 \mathrm{~h}$, after which time the system was allowed to cool to room temperature under argon flow.

Raman spectroscopy was carried out using a Horiba/Jobin-Yvon LABRAM-HR spectrometer with the $632.8 \mathrm{~nm}$ line of a helium-neon laser (effective power of $6 \mathrm{~mW}$ at the sample surface) as excitation source, diffraction gratings of 600 and 1800 grooves $/ \mathrm{mm}$, Peltier-cooled CCD detector, confocal Olympus microscope (100× magnification), and experimental resolution of typically $1 \mathrm{~cm}^{-1}$ for 10 accumulations of $30 \mathrm{~s}$.

The powder XRD data were obtained in a Rigaku model Geigerflex equipment using $\mathrm{CuK \alpha}$ radiation and scanning from $2^{\circ}$ to $75^{\circ}(2 \theta)$ at a scan rate of $4 \mathrm{~min}^{-1}$. Magnetization measurements were carried out in a magnetometer LakeShore 7404 VSM System. The surface area was determined by nitrogen adsorption using the BET method with 22 nitrogen adsorption/desorption cycles in an Autosorb 1 Quantachrome instrument. Scanning electron microscopy (SEM) analyses were carried out in a Jeol JSM 840A and a Quanta 200 ESEM-FEG from FEI. Adsorption experiments were carried out with $30 \mathrm{mg}$ of the magnetic composites and $5 \mathrm{~mL}$ of quinoline, dibenzonthiophene or dye (methylene blue or indigo carmine) solutions $\left(50 \mathrm{mg} \mathrm{L}^{-1}\right)$. All systems were kept for $24 \mathrm{~h}$ at room temperature. The concentrations of the dyes were measured by UV/Vis spectrophotometry using an UV mini-1240 Shimadzu. The consumption of quinoline and dibenzothiophene were monitored by gas chromatography (Shimadzu, GC17A model equipped with a FID detector) using an Equity-5 column and argon as carrier gas. Zeta potential at different $\mathrm{pH}$ 's were measurement using a Dispersion Techonoly, Inc., model: DT1200 SN:447.

\section{Results and discussion}

\subsection{Preparation and characterization of magnetic composites}

The magnetic composites were prepared by chemical vapor deposition reaction with ethanol as the carbon source at 700, 800 and $900^{\circ} \mathrm{C}$, using $\mathrm{NiO}$ and NiMo oxides, which are not magnetic, as starting materials. All the materials became strongly magnetic after the ethanol/CVD process and presented very low specific area $c a$. $15 \mathrm{~m}^{2} / \mathrm{g}$, which is expected considering the preparation method.

Diffractogram patterns of the materials (Fig. 1a) showed that the ethanol reduced $\mathrm{Ni}^{2+}(\mathrm{NiO})$ to form $\mathrm{Ni} / \mathrm{C}$ composites. Metallic nickel was formed at $700^{\circ} \mathrm{C}$ and a small amount of carbon was produced on its surface (Fig. 1a in detail). When molybdenum is introduced (NiMo oxides) the formation of carbon is preferentially observed at $700^{\circ} \mathrm{C}$. However, at higher temperatures $\left(800-900^{\circ} \mathrm{C}\right)$ the carbon amount decreases to form higher quantities of molybdenum carbide, $\mathrm{Mo}_{2} \mathrm{C}$. The presence of metallic nickel in all samples can explain the magnetic behavior of the materials due to its high saturation magnetization presented by $\mathrm{Ni}^{0}$. This magnetic property is very useful to the adsorption applications that allow the materials to be easily removed from de reactions system by application of a magnetic field.

Regarding the removal of the magnetic particles from a catalytic reaction by means of the application of a magnetic force, this magnetic force will be proportional to the field gradient applied and to the magnetic moment of the particles. Hence, the magnetic force acting in the particle will be proportional to its magnetization. In consequence if the field applied is sufficient to saturate the particle then the magnetic force will be proportional to the saturation magnetization of the particle. The magnetic properties of these materials are strategic and very important for the intended application. Being magnetic, the materials can be removed easily from a 

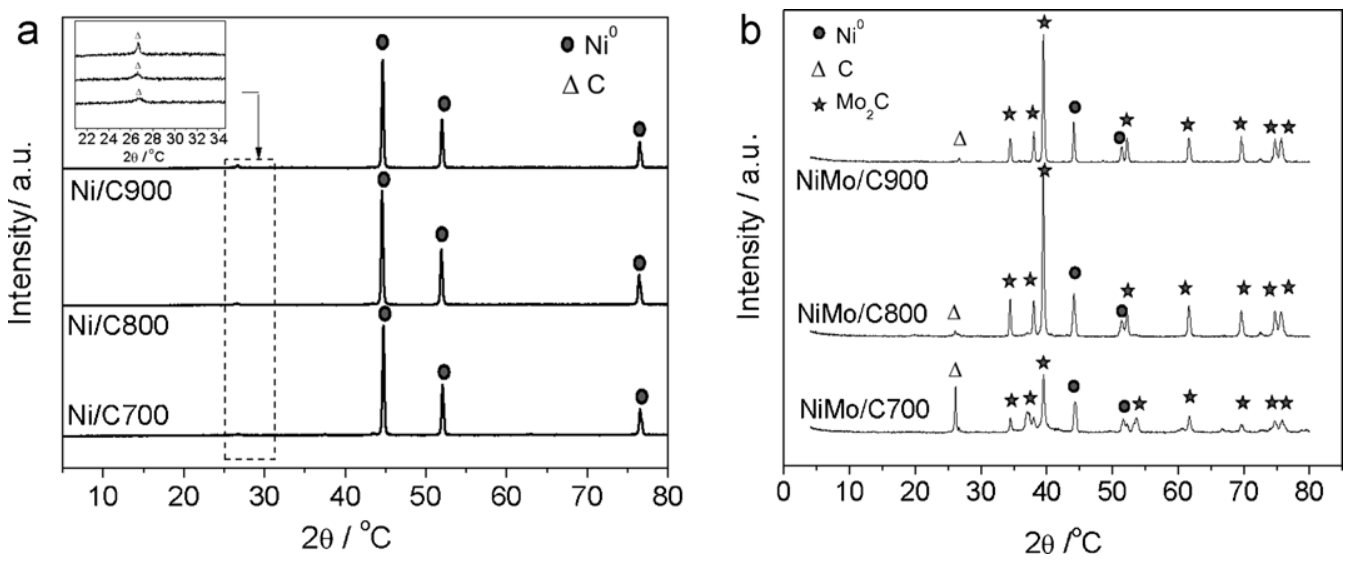

Fig. 1. XRD for the $\mathrm{Ni} / \mathrm{C}(\mathrm{a})$ and $\mathrm{Ni} / \mathrm{Mo}_{2} \mathrm{C}(\mathrm{b})$, after ethanol/CVD process at different temperatures.

reaction system after application of a magnetic field gradient and be pulled into the strongest magnetic field region facilitating their removal [29].

The room-temperature magnetization curve (Fig. 2) shows a saturation magnetization value of 49.9 and $13.2 \mathrm{emu} \mathrm{g}^{-1}$, for Ni/C 800 and $\mathrm{Ni} / \mathrm{Mo}_{2} \mathrm{C} 800$, respectively. These saturation magnetization values are coherent once the sample $\mathrm{Ni} / \mathrm{C}$ presents higher amount of $\mathrm{Ni}$ compared to $\mathrm{Ni} / \mathrm{Mo}_{2} \mathrm{C}$.

Scanning electron micrographs of $\mathrm{Ni}$ and NiMo oxides after ethanol/CVD process are shown in Figs. 3 and 4, respectively. Ni particles were partially coated with filamentous carbon as can be seen in the SEM images of all NiO samples after CVD (Fig. 3). In some cases it is possible to observe carbon filaments, approximately $1 \mu \mathrm{m}$ long and diameters of a few nanometers and also some Ni particles completely coated by carbon. In contrast, when Mo is introduced in the sample the morphology completely changes (Fig. 4). The ethanol/CVD process of NiMo oxides produces higher amounts of coated materials probably by the formation of molybdenum carbide as suggested by XRD.

Further information regarding the carbon structures was obtained by Raman spectroscopy (Fig. 5). In the Raman spectra of the NiO after CVD it is possible to see two intense bands attributed to $\mathrm{D}$ and $\mathrm{G}$-bands of carbon materials, suggesting the formation of the Ni/C composites. The G-band, related to the vibration of $\mathrm{sp}^{2}$ hybridized carbon in the two-dimensional graphite for ordered carbon species, can be observed at $1578 \mathrm{~cm}^{-1}$. The D-band is highly

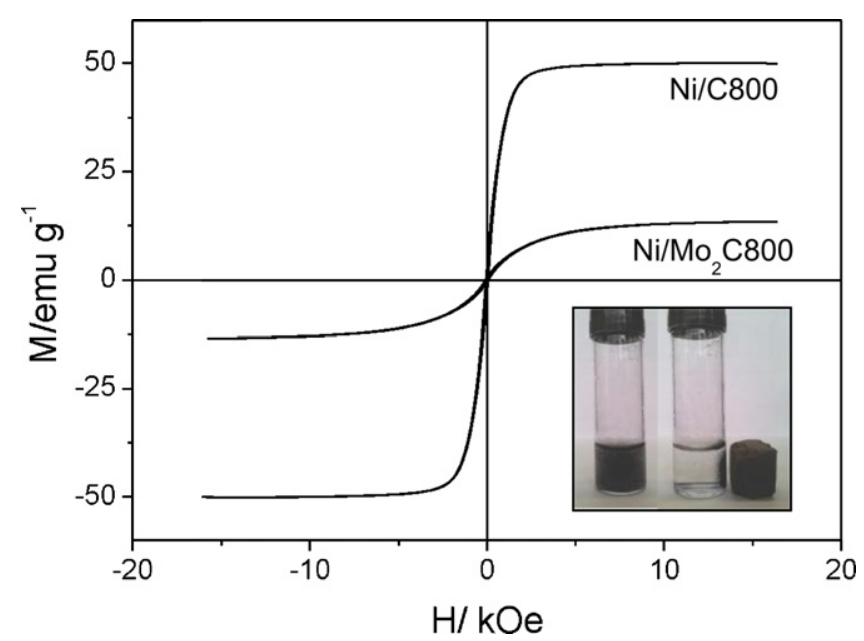

Fig. 2. Magnetic hysteresis curves for the $\mathrm{Ni} / \mathrm{C} 800$ and $\mathrm{NiMo} / \mathrm{C} 800$ materials and in detail magnetic separation of the materials after utilization. sensitive to amorphous carbon or defects in the carbon materials and appears at $1331 \mathrm{~cm}^{-1}$ and can be ascribed to the defects in the fibrous carbon structure. The intensity of the D-band in comparison with the graphitic carbon G-band suggests that defective carbon is more abundant in the sample after ethanol/CVD at $700^{\circ} \mathrm{C}$. The more intense and narrow G-band with $I_{\mathrm{G}} / I_{\mathrm{D}}$ ratio of 4.3 , observed as the ethanol/CVD process temperature increases, reflects the more organized and crystalline carbon structures. This organized carbon was also observed in the XRD patterns with reflection peaks with $2 \theta$ at approximately $26^{\circ}$.

The Raman spectra of the $\mathrm{Ni} / \mathrm{Mo}_{2} \mathrm{C}$ material after the ethanol/CVD process shows characteristic bands of molybdenum carbide, $\mathrm{Mo}_{2} \mathrm{C}$ [30], as the main product, in agreement of XRD patterns. Also some peaks can be observed related to $G$ and $D$ band for carbon.

The amounts of carbon deposited on the materials were estimated by thermal analysis TG/DTG (Fig. 6). For all Ni/C composites, it is possible to observe a weight loss between 500 and $620^{\circ} \mathrm{C}$ related to carbon oxidation according to Eq. (1), and a weight gain related to Ni oxidation (Eq. (2)) at higher temperatures (Fig. 6a and b).

$$
\begin{aligned}
& \mathrm{C}(\mathrm{s})+\mathrm{O}_{2}(\mathrm{~g}) \rightarrow \mathrm{CO}_{2}(\mathrm{~g}) \\
& \mathrm{Ni}(\mathrm{s})+1 / 2 \mathrm{O}_{2}(\mathrm{~g}) \rightarrow \mathrm{NiO}(\mathrm{s})
\end{aligned}
$$

Therefore, the results clearly show that the temperature of the ethanol/CVD process directly affects the amount of carbon deposited on the surface of the materials with 14,16 and $19 \%$, for the samples treated at 700,800 and $900{ }^{\circ} \mathrm{C}$, respectively. Also, it is interesting to observe from DTG curves (Fig. 6b) that the velocity of carbon decomposition is different for the materials prepared at 700,800 and $900^{\circ} \mathrm{C}$. For the sample Ni/C 700 the carbon decomposes in a maximum of velocity at $512^{\circ} \mathrm{C}$ and for the materials $\mathrm{Ni} / \mathrm{C}$ 800 this temperatures is much higher of $616^{\circ} \mathrm{C}$. These results suggest that the carbon deposited during the CVD process at $800^{\circ} \mathrm{C}$ is more stable and crystalline than the carbon deposited at $700^{\circ} \mathrm{C}$. These results are in agreement with the ones obtained by XRD with a slight increase in the intensity of the peak attributed to the carbon as well as by Raman spectroscopy that presents a pronounced increase in the intensity of the $\mathrm{G}$ band, related to better graphitized carbon, and specially in $I_{G} / I_{D}$ ratio with the increase in the temperature of CVD process.

The thermal behavior of the material completely changes with the addition of molybdenum. It is possible to observe an initial weight gain after $350{ }^{\circ} \mathrm{C}$ related to the $\mathrm{Ni}$ oxidation (Eq. (2)). At higher temperatures $\left(\mathrm{ca} .800^{\circ} \mathrm{C}\right)$ it is possible to observe a weight loss that can be related to decomposition of the very stable 


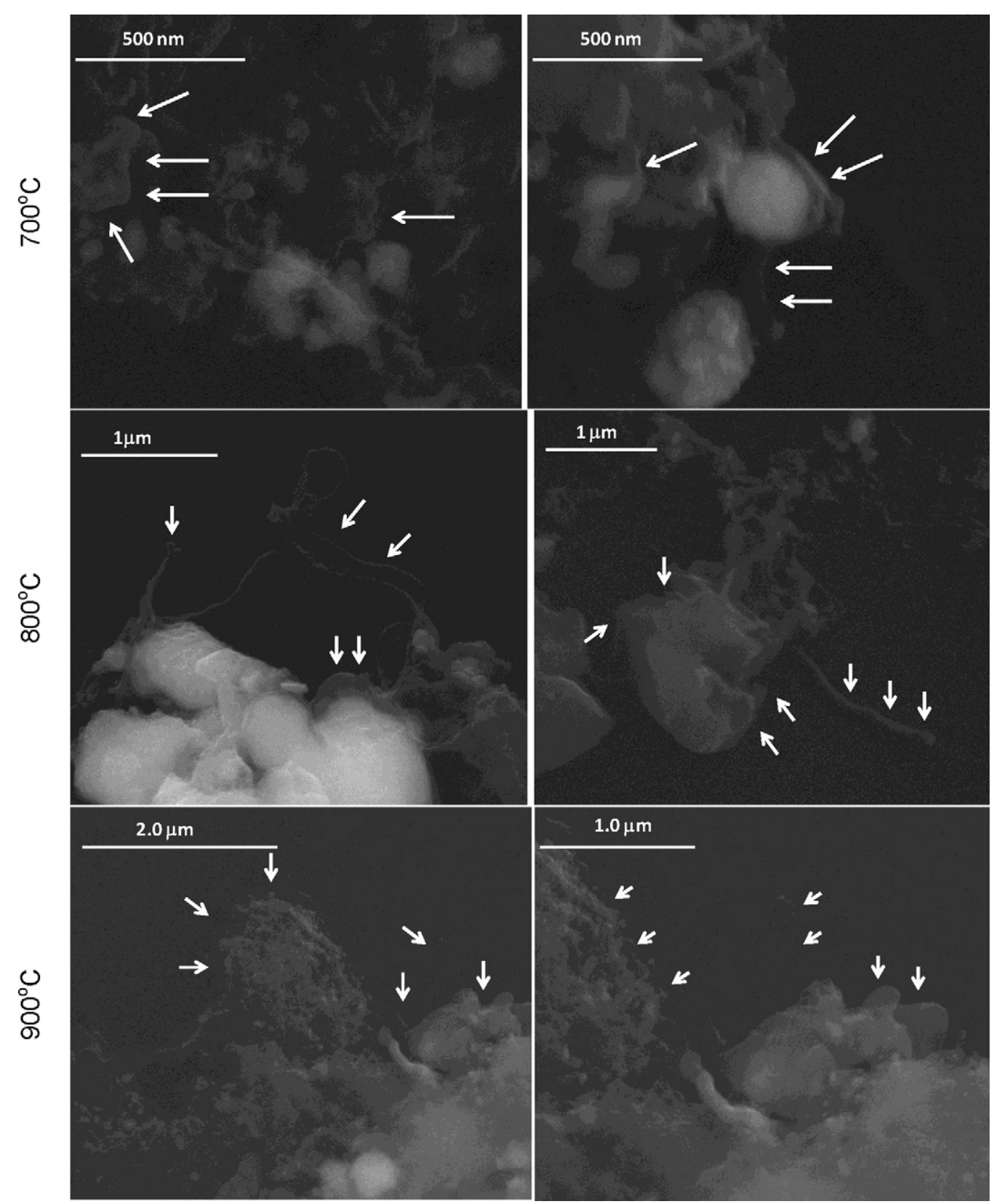

Fig. 3. SEM images of $\mathrm{Ni} / \mathrm{C}$ obtained by ethanol/CVD process at $700^{\circ} \mathrm{C}(\mathrm{Ni} / \mathrm{C} 700), 800^{\circ} \mathrm{C}(\mathrm{Ni} / \mathrm{C} 800)$, and $900{ }^{\circ} \mathrm{C}(\mathrm{Ni} / \mathrm{C} 900)$.

molybdenum carbide, forming molybdenum oxide (Eq. (3)), confirmed by the XRD results obtained for the TG residue.

$\mathrm{Mo}_{2} \mathrm{C}(\mathrm{s})+4 \mathrm{O}_{2}(\mathrm{~g}) \rightarrow 2 \mathrm{MoO}_{3}(\mathrm{~s})+\mathrm{CO}_{2}(\mathrm{~g})$

Also, a strong increase in the amount (50\%) of carbon deposited as carbide on the materials is observed for the $\mathrm{Ni} / \mathrm{Mo}_{2} \mathrm{C}$ materials (Fig. $6 \mathrm{c}$ and d) at $900^{\circ} \mathrm{C}$.

TG results strongly indicate that the carbonaceous materials in $\mathrm{Ni} / \mathrm{Mo}_{2} \mathrm{C}$ materials are completely different from those without Mo. The first one decomposes at $700^{\circ} \mathrm{C}$ and for the latter the decomposition starts at $480^{\circ} \mathrm{C}$. We believe that these results are related to the decomposition of very stable and highly crystalline molybdenum carbide formed during the CVD process, as observed by XRD. On the other hand, the oxidation of carbon at $480^{\circ} \mathrm{C}$ is related to the formation of a less crystalline carbon, such as graphite or carbon filaments. It is easy to observe that the temperature of nickel oxidation increase with the temperature of CVD. Probably the highest the temperature of CVD the higher the coating of Ni particles by $\mathrm{Mo}_{2} \mathrm{C}$, making the $\mathrm{Ni}$ more difficult to oxidize.

From the results presented above we proposed that the ethanol decomposition mechanism to form the carbonaceous phases in the solid phase seems to be different in the molybdenum presence. Metallic nickel showed activity for ethanol decomposition, especially at high temperatures, to form graphitic or amorphous carbon. However, in the presence of molybdenum, initially the reaction with ethanol takes place with the activation of ethanol to form atomic carbon on the surface of the particles with chemical reduction of $\mathrm{Ni}$ and Mo. In a second step, the reduced molybdenum is able to react with the carbon to form highly crystalline and stable molybdenum carbide. In this step, the surface of nickel remains in the metallic form $\left(\mathrm{Ni} / \mathrm{Mo}_{2} \mathrm{C}\right)$. It is interesting to note that the presence of molybdenum inhibits the formation of graphitic carbon on the nickel surface (Fig. 7), which avoids the poisoning of surface nickel with carbon deposits. 

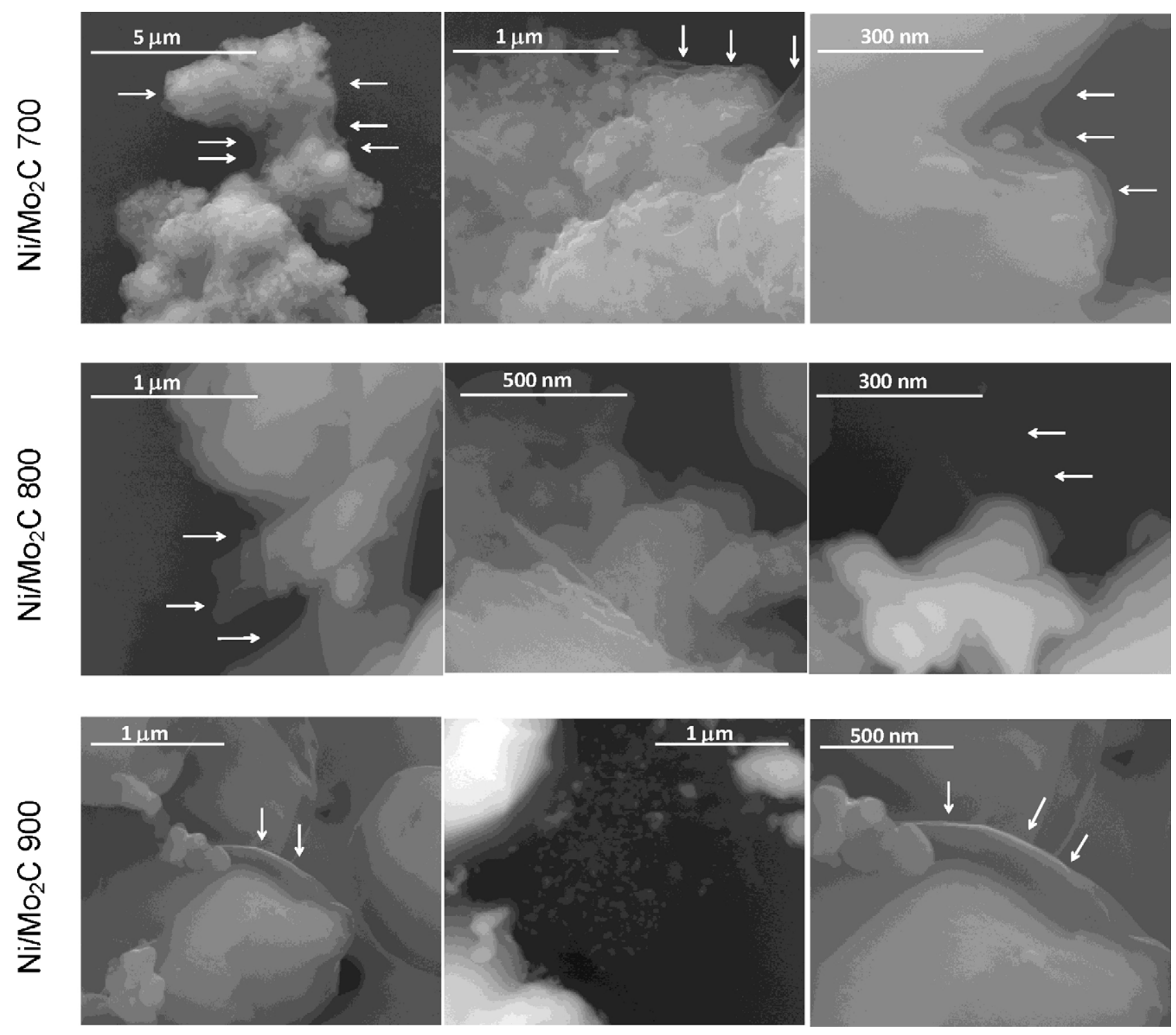

Fig. 4. SEM images of $\mathrm{Ni} / \mathrm{Mo}_{2} \mathrm{C}$ obtained by ethanol/CVD process at $700^{\circ} \mathrm{C}, 800$, and $900^{\circ} \mathrm{C}$.

The formation of the $\mathrm{Ni} / \mathrm{Mo}_{2} \mathrm{C}$ composite was studied with different amounts of molybdenum. The CVD process was carried out with Ni oxide impregnated with different Ni:Mo molar ratio (NiMo, $\mathrm{NiMo}_{0.5}$ and $\left.\mathrm{NiMo}_{0.25}\right)$.

The XRD (Fig. 8) and Raman (Fig. 9) analyses of the materials show that the molybdenum carbide amount increases with the molybdenum impregnation. This increase happens concomitantly with a decrease of carbon formation. These results are in agreement with the proposal in Fig. 7 that molybdenum favors the activation of ethanol compared to the carbon formation on the nickel surface.

\subsection{Adsorption studies}

The magnetic $\mathrm{Ni} / \mathrm{C}$ and $\mathrm{Ni} / \mathrm{Mo}_{2} \mathrm{C}$ materials obtained by CVD at different temperatures were used as adsorbents for different contaminants, i.e. dibenzothiophene, quinoline, and organic dyes methylene blue (MB) and indigo carmine (IC). The obtained results are shown in Figs. 10 and 11.

The adsorption of IC dye in the $\mathrm{Ni} / \mathrm{C}$ composites is low, 32, 22 and $22 \%$ for the materials treated at 700,800 and $900{ }^{\circ} \mathrm{C}$, respectively. The adsorption of $\mathrm{MB}$ was lower (less than 10\%) for all Ni/C materials (Fig. 10a).

After addition of $\mathrm{Mo}, \mathrm{Ni} / \mathrm{Mo}_{2} \mathrm{C}$, it is possible to observe that the adsorption capacity strongly increases (Fig. 10b). This is likely due to interactions of the molybdenum carbide coating with the dye molecules. Moreover, it is worth noting that the treatment temperature led to a completely different behavior of the adsorption properties of the materials.

Adsorption of IC dye on composites treated at 700 and $800^{\circ} \mathrm{C}$ are relatively low, i.e., 43 and 31\%, respectively. However, the adsorption of methylene blue is very high, reaching almost $100 \%$ after $20 \mathrm{~min}$. A different behavior was observed for the composite treated at $900{ }^{\circ} \mathrm{C}$ with adsorption capacities of $34 \%$ for methylene blue and $99 \%$ for indigo carmine. These results suggest that, beyond the hydrophobic interaction, the electronic characteristics of the dyes are also an important factor in the adsorption properties on the materials surface.

In order to understand these electrostatic interactions between the dyes and the adsorbent materials, zeta potential measurements at different $\mathrm{pH}$ were carried out (Fig. 12). The zeta potential at different $\mathrm{pH}$ curves allows the determination of the point of zero charge 

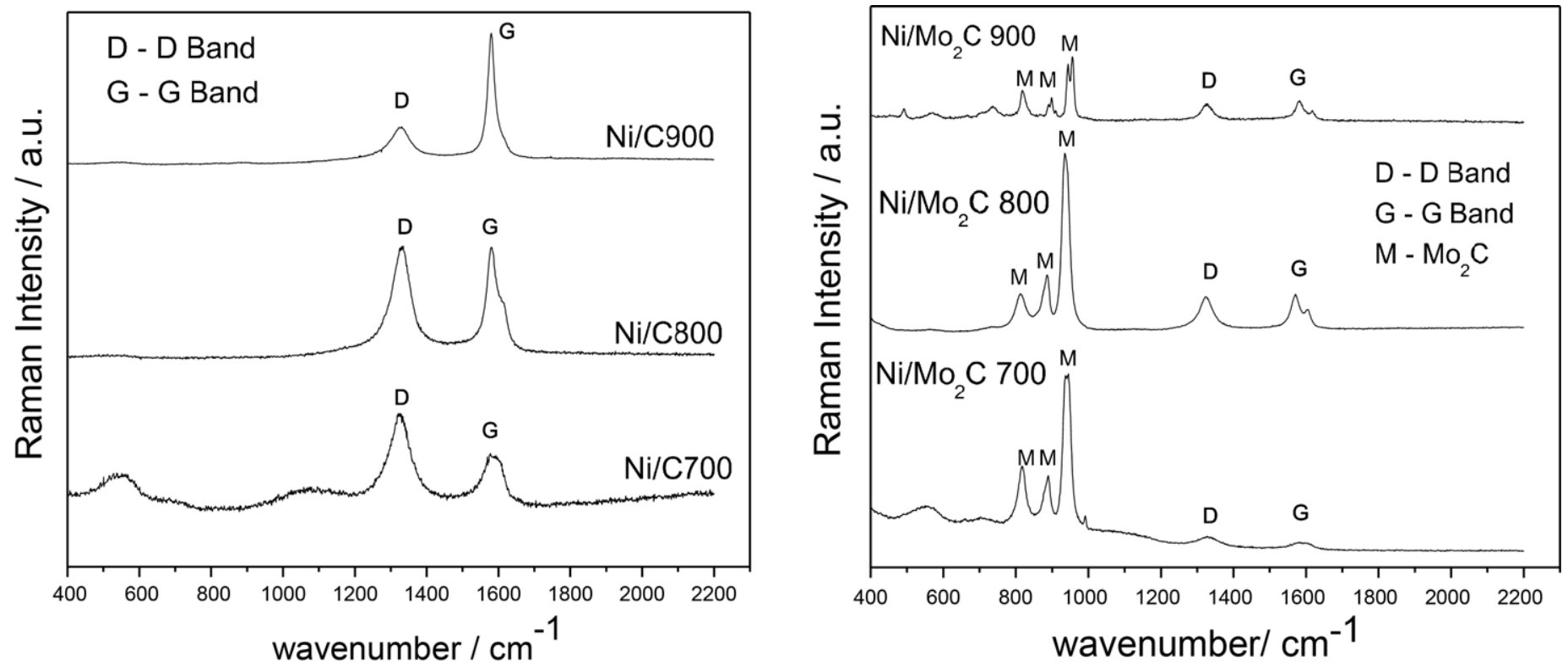

Fig. 5. Raman spectra of the composite $\mathrm{Ni} / \mathrm{C}(\mathrm{a})$ and $\mathrm{Ni} / \mathrm{Mo}_{2} \mathrm{C}(\mathrm{b})$, obtained after ethanol/CVD process at different temperatures.
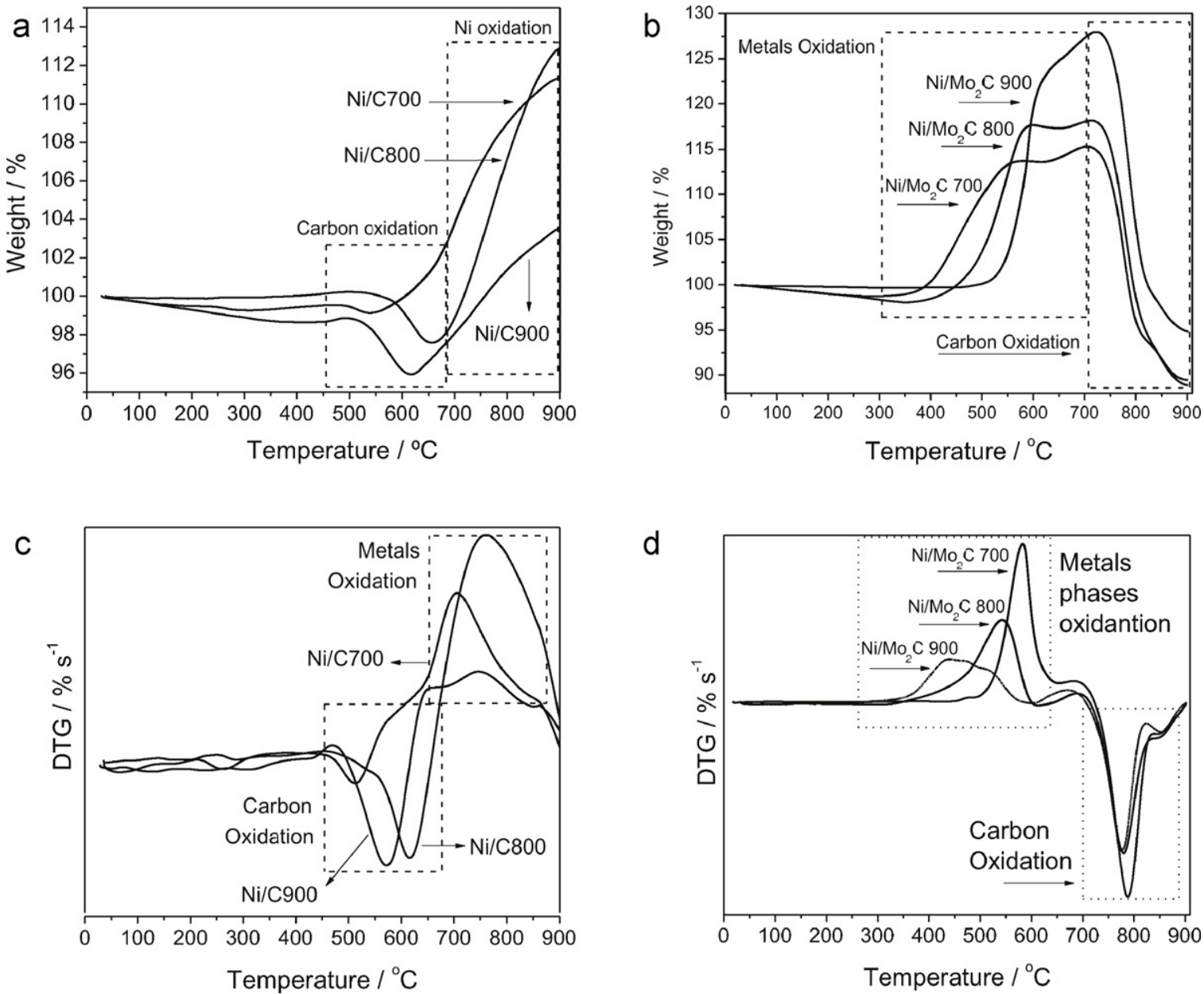

Fig. 6. TG and DTG curves of the $\mathrm{Ni} / \mathrm{C}\left(\mathrm{a}\right.$ and $\mathrm{b}$ ) and $\mathrm{Ni} / \mathrm{Mo}_{2} \mathrm{C}$ (c and d), obtained after ethanol/CVD process at different temperatures, in air. 

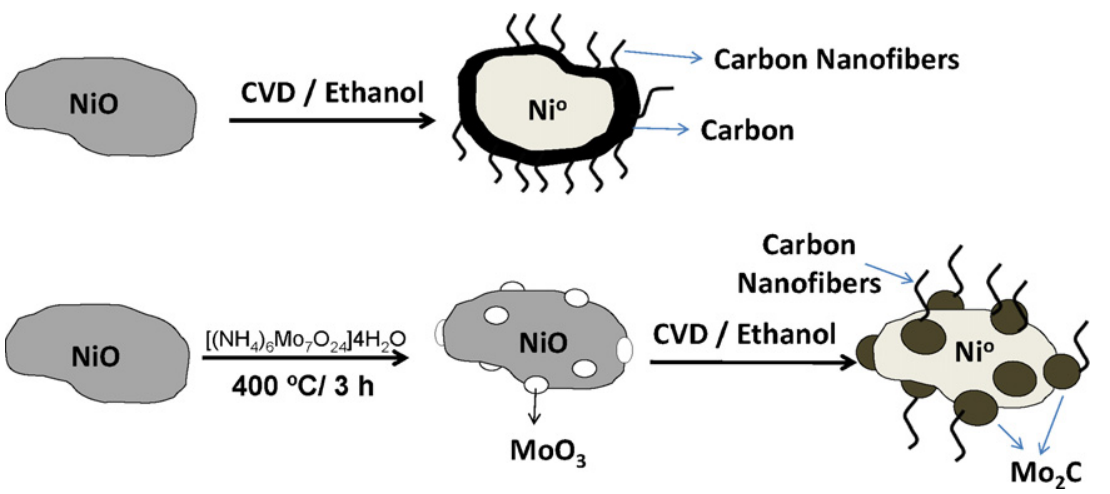

Fig. 7. Representation of the reaction of $\mathrm{Ni}$ and NiMo oxides with ethanol during the CVD process to form the magnetic composites.

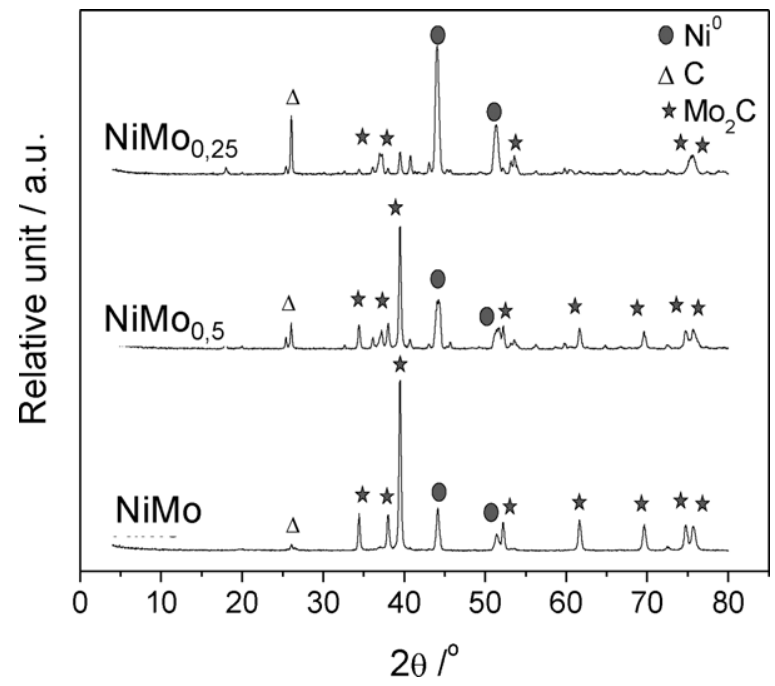

Fig. 8. XRD analyses of the $\mathrm{Ni} / \mathrm{Mo}_{2} \mathrm{C}$ with different amounts of molybdenum, obtained by CVD of ethanol at $800^{\circ} \mathrm{C}$.

(PZC) of the materials and an evaluation of the surface charge of the particles under study.

Fig. 12 shows a point of zero charge (PZC) at $\mathrm{pH} 2.6$ and 3.0 for the $\mathrm{Ni} / \mathrm{Mo}_{2} \mathrm{C} 700$ and $\mathrm{Ni} / \mathrm{Mo}_{2} \mathrm{C} 800$ materials, respectively. Since the initial $\mathrm{pH}$ of the dye solutions was 4.0 , those results indicated that the surface of the materials is negatively charged and therefore preferentially adsorb positively charged molecules such as methylene blue dye. On the other hand, the $\mathrm{Ni} / \mathrm{Mo}_{2} \mathrm{C} 900$ material,

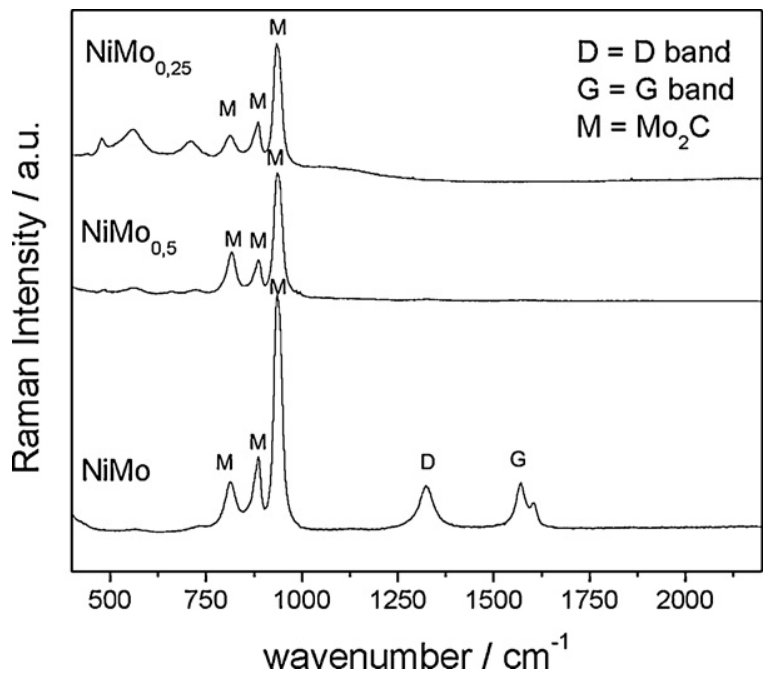

Fig. 9. Raman spectra of the $\mathrm{Ni} / \mathrm{Mo}_{2} \mathrm{C}$ with different amounts of molybdenum, obtained by CVD of ethanol at $800^{\circ} \mathrm{C}$.

with PZC at $\mathrm{pH}$ 5.1, would have a positively charged surface at $\mathrm{pH}$ 4.0 and therefore would absorb more anionic dyes such as indigo carmine.

The type of carbon produced by the CVD process, in the presence of Mo, may explain the higher adsorption properties of the $\mathrm{Ni} / \mathrm{Mo}_{2} \mathrm{C}$ composites, once the specific area are very similar for all the materials. Moreover, chemical groups such as phenolic, carboxilic acid a<smiles>O=C1/C(=C2\Nc3ccc(S(=O)(=O)[O-])cc3C2=O)Nc2ccc(S(=O)(=O)[O-])cc21</smiles>

b<smiles>CN(C)c1ccc2nc3ccc(=[N+](C)C)cc-3sc2c1</smiles>

d<smiles>c1ccc2ncccc2c1</smiles>

Fig. 10. Structure of methylene blue (a), indigo carmine (b), dibenzothiophene (c), and quinoline (d). 

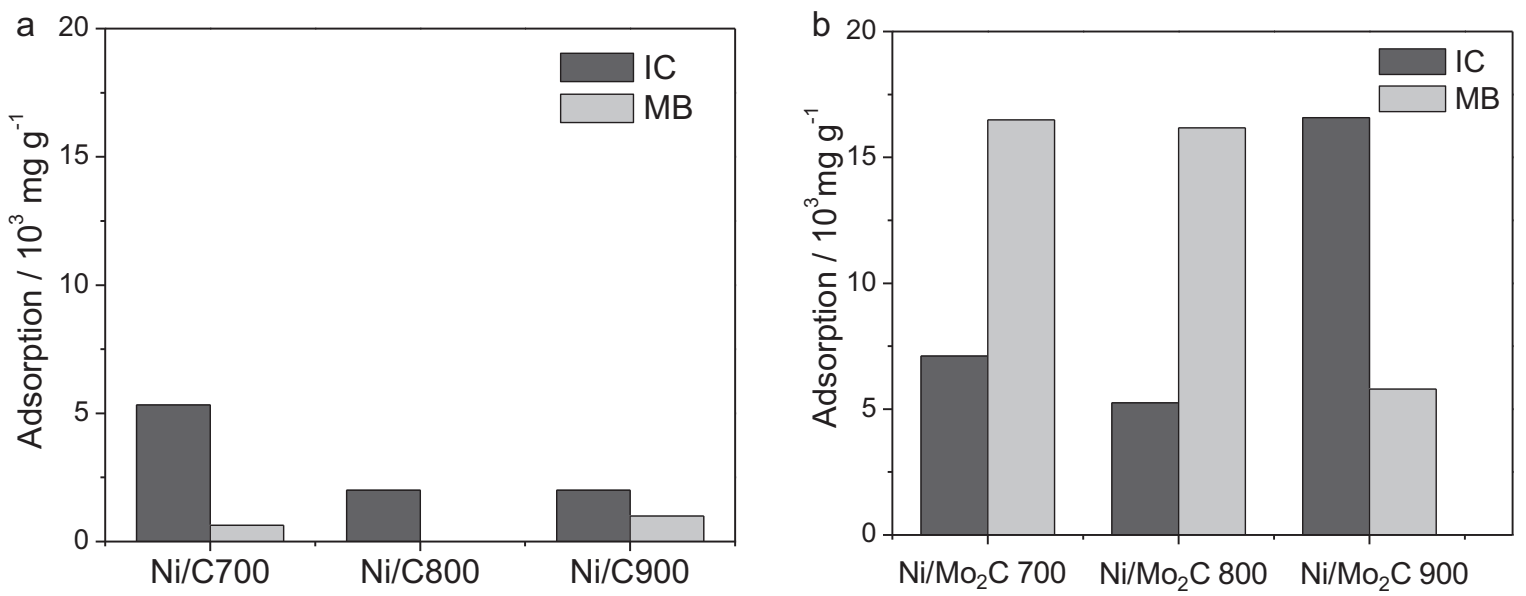

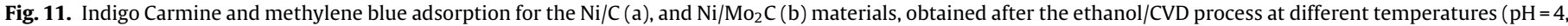
natural $\mathrm{pH}$ of the dye solution).

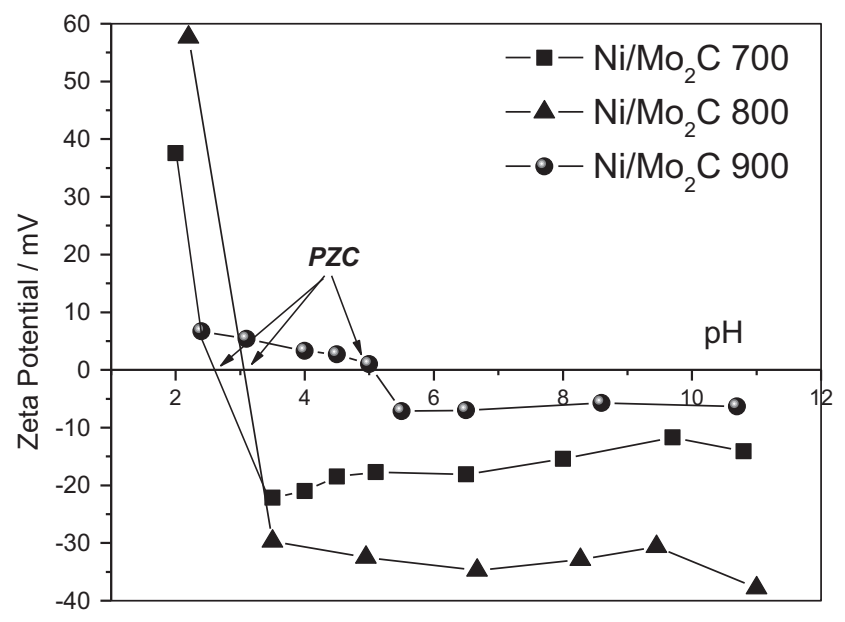

Fig. 12. Zeta potential measurements for $\mathrm{Ni} / \mathrm{Mo}_{2} \mathrm{C}$ materials obtained after ethanol/CVD process at 700,800 and $900^{\circ} \mathrm{C}$.

can be formed on the carbon, which can influence the adsorption process.

Another group of pollutants (nitrogen and sulfur compounds) was tested in the adsorption process. The preliminary results are displayed in Fig. 13. In general, the molybdenum carbide presents a slightly better adsorption capacity compared to the material without Mo. The best adsorbent was the $\mathrm{Ni} / \mathrm{Mo}_{2} \mathrm{C} 700$ with an adsorption capacity of approximately $20 \mathrm{mg} \mathrm{g}^{-1}$, which is higher in comparison with other materials described in the literature.

The magnetic properties can be useful for the separation of the adsorbent from the reaction mixture, which may be recovered after been used in the adsorption process. The material with adsorbed pollutants was separated by a magnetic field, from the mixture. Then, the material was washed with ethanol to release the pollutants, dried at $60^{\circ} \mathrm{C}$, and the regenerated materials were used as adsorbent in a new solution. After 4 cycles of adsorption/desorption the sample still showed almost the same adsorption capacity (Supplementary material).

Analyses of the liquid mixtures after the adsorption experiements by atomic absorption spectrometry did not show any significant concentration of $\mathrm{Ni}$ or Mo ions in solution. Moreover, kinetic experiments showed that the adsorption stopped when the material was magnetically removed from the medium. These results strongly suggest the occurrence of the adsorption in heterogeneous phase.

These results and promising catalytic activity accredited them to be used in catalytic processes that use catalysts to replace noble metals as an active phase.
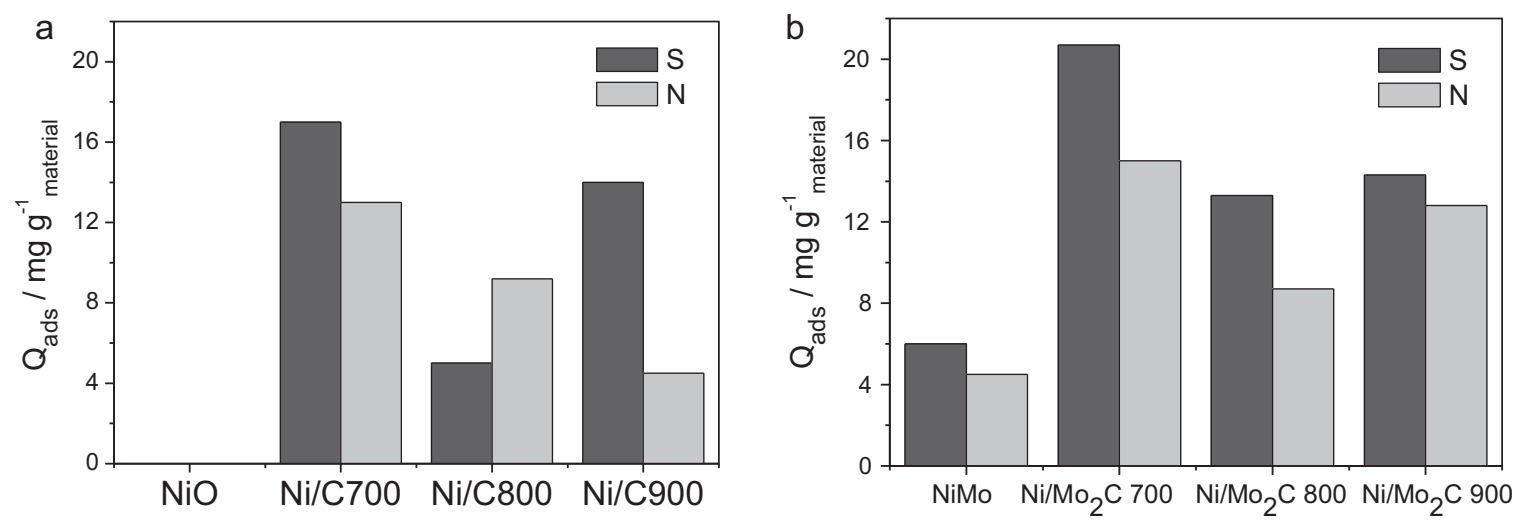

Fig. 13. Adsorption of dibenzothiophene and quinoline on $\mathrm{Ni} / \mathrm{C}(\mathrm{a})$, and $\mathrm{Ni} / \mathrm{Mo}_{2} \mathrm{C}(\mathrm{b})$ obtained after ethanol/CVD process at different temperatures. 


\section{Conclusion}

The CVD reaction of $\mathrm{Ni}$ and NiMo oxides with ethanol at temperatures ranging from $700-900{ }^{\circ} \mathrm{C}$ produces magnetic composites based on Ni magnetic particle with carbonaceous material deposits $\mathrm{Ni} / \mathrm{C}$ and $\mathrm{Ni} / \mathrm{Mo}_{2} \mathrm{C}$.

Preliminary studies in the use of the magnetic composites as adsorbent of model dyes and especially for dibenzothiophene and quinoline, important contaminants in the liquid fuels present great potential to be used in technological applications. The great advantage of these composites is that they could be easily recovered magnetically and reused.

\section{Acknowledgements}

The financial support for this research work provide by FAPEMIG, CNPq and CAPES is gratefully acknowledged. We also thank the UFMG microscopy center for the use of the SEM facilities.

\section{Appendix A. Supplementary data}

Supplementary data associated with this article can be found, in the online version, at http://dx.doi.org/10.1016/ j.jhazmat.2012.09.002.

\section{References}

[1] T. Chen, B. Yang, S. Li, K. Wang, X. Jiang, Y.Zhang, G. He, $\mathrm{Ni}_{2} \mathrm{P}$ catalysts supported on titania-modified alumina for the hydrodesulfurization of dibenzothiophene, Ind. Eng. Chem. Res. 50 (2011) 11043-11048.

[2] N.M. Schweitzer, J.A. Schaidle, O.K. Ezekoye, X. Pan, S. Linic, L.T. Thompson, High activity carbide supported catalysts for water gas shift, J. Am. Chem. Soc. 133 (2011) 2378-2381.

[3] Z.-Q. Wang, Z.-B. Zhang, M.-H. Zhang, The efficient synthesis of a molybdenum carbide catalyst via $\mathrm{H}_{2}$-thermal treatment of a Mo(vi)hexamethylenetetramine complex, Dalton Trans. 40 (2010) 1098-1104.

[4] S. Cetinkaya, S. Eroglu, Thermodynamic analysis and synthesis of porous $\mathrm{Mo}_{2} \mathrm{C}$ sponge by vapor-phase condensation and in situ carburization of $\mathrm{MoO}_{3}$, J. Alloys Compd. 489 (2010) 36-41.

[5] Z. Yao, Z. Lai, X. Zhang, F. Peng, H. Yu, H. Wang, Structural stability and mutual transformations of molybdenum carbide, nitride and phosphide, Mater. Res. Bull. 46 (2011) 1938-1941.

[6] T.C. Xiao, H.T. Wang, J.W. Da, K.S. Coleman, M.L.H. Green, Study of the preparation and catalytic performance of molybdenum carbide catalysts prepared with $\mathrm{C}_{2} \mathrm{H}_{2} / \mathrm{H}-2$ carburizing mixture, J. Catal. 211 (2002) 183-191.

[7] A.F. Lamic, C.H. Shin, G. Djega-Mariadassou, C. Potvin, Characterization of $\mathrm{Mo}_{2} \mathrm{C}-\mathrm{WO}_{2}$ composite catalysts for bifunctional isomerization: a new pulse method to quantify acid sites, Appl. Catal. A 302 (2006) 5-13.

[8] C.S. Castro, M.C. Guerreiro, M. Gonçalves, L.C.A. Oliveira, A.S. Anastácio, Activated carbon/iron oxide composites for the removal of atrazine from aqueous medium, J. Hazard. Mater. 164 (2009) 609-614.

[9] C.M. Piqueras, I.O. Costilla, P.G. Belelli, N.J. Castellani, D.E. Damiani, Pd$\gamma \mathrm{Al}_{2} \mathrm{O}_{3}$ applied to triglycerides hydrogenation with supercritical propane: experimental and theoretical catalysts characterization, Appl. Catal. A 347 (2008) 1-10.
[10] D.L.J. Thorek, A. Chen, J. Czupryna, A. Tsourkas, Superparamagnetic iron oxide nanoparticle probes for molecular imaging, Ann. Biomed. Eng. 34 (2006) 23-38.

[11] D.E. Sosnovik, M. Nahrendorf, R. Weissleder, Magnetic nanoparticles for MR imaging: agents, techniques and cardiovascular applications, Basic Res. Cardiol. 103 (2008) 122-130.

[12] F. Yang, C. Jin, S. Subedi, C.L. Lee, Q. Wang, Y.J. Jiang, J. Li, Y. Di, D.L. Fu, Emerging inorganic nanomaterials for pancreatic cancer diagnosis and treatment, Cancer Treat. Rev. 38 (2012) 566-579.

[13] Z.H. Sun, L.F. Wang, P.P. Liu, S.C. Wang, B. Sun, D.Z. Jiang, F.S. Xiao, Magnetically motive porous sphere composite and its excellent properties for the removal of pollutants in water by adsorption and desorption cycles, Adv. Mater. 18 (2006) 1968-1973.

[14] S.B.C. Pergher, L.C.A. Oliveira, A. Smaniotto, D.I. Petkowicz, Magnetic zeolites for removal of metals in water, Quim. Nova 28 (2005) 751-755.

[15] L.C.R. Machado, F.W.J. Lima, R. Paniago, J.D. Ardisson, K. Sapag, R.M. Lago, Polymer coated vermiculite-iron composites: novel floatable magnetic adsorbents for water spilled contaminants, Appl. Clay Sci. 31 (2006) 207-215.

[16] I.R. Guimarães, L.C.A. Oliveira, P.F. Queiroz, T.C. Ramalho, M. Pereira, J.D. Fabris, J.D. Ardisson, Modified goethites as catalyst for oxidation of quinoline: evidence of heterogeneous Fenton process, Appl. Catal. A 347 (2008) 89-93.

[17] L.C.A. Oliveira, R.V.R.A. Rios, J.D. Fabris, V. Garg, K. Sapag, R.M. Lago, Activated carbon/iron oxide magnetic composites for the adsorption of contaminants in water, Carbon 40 (2002) 2177-2183.

[18] S. Veintemillas-Verdaguer, Y. Leconte, R. Costo, O. Bomati-Miguel, B. BouchetFabre, M.P. Morales, P. Bonville, S. Pérez-Rial, I. Rodriguez, N. Herlin-Boime, Continuous production of inorganic magnetic nanocomposites for biomedical applications by laser pyrolysis, J. Magn. Magn. Mater. 311 (2007) 120-124.

[19] G.M. Shi, Z.D. Zhang, H.C. Yang, $\mathrm{Al}_{2} \mathrm{O}_{3} / \mathrm{Fe}_{2} \mathrm{O}_{3}$ composite-coated polyhedral Fe nanoparticles prepared by arc discharge, J. Alloy Comps. 384 (2004) 296-299.

[20] Z. Wang, P. Xiao, N. He, Synthesis and characteristics of carbon encapsulated magnetic nanoparticles produced by a hydrothermal reaction, Carbon 44 (2006) 3277-3284.

[21] P.Y. Keng, I. Shim, B.D. Korth, J.F. Douglas, J. Pyun, Synthesis, Self-assembly of polymer-coated ferromagnetic nanoparticles, ACS Nano 1 (2007) 279-292.

[22] E.N. Konyushenko, N.E. Kazantseva, J. Stejskal, M. Trchova, J. Kovarova, I. Sapurina, M.M. Tomishko, O.V. Demicheva, J. Prokes, Ferromagnetic behaviour of polyaniline-coated multi-wall carbon nanotubes containing nickel nanoparticles, J. Magn. Magn. Mater. 320 (2008) 231-240.

[23] S. Gyergyek, M. Huskic, D. Makovec, M. Drofenik, Superparamagnetic nanocomposites of iron oxide in a polymethyl methacrylate matrix synthesized by in situ polymerization, Colloids Surf. A 317 (2008) 49-55.

[24] M.K. Hong, B.J. Park, H.J. Choi, Preparation and physical characterization of polyacrylamide coated magnetite particles, Phys. Status Solidi 204 (2007) 4182-4185.

[25] L.C.A. Oliveira, E. Pereira, I.R. Guimaraes, A. Vallone, M. r. Pereira, J.P. Mesquita, K. Sapag, Preparation of activated carbons from coffee husks utilizing $\mathrm{FeCl}_{3}$ and $\mathrm{ZnCl}_{2}$ as activating agents, J. Hazard. Mater. 165 (2009) 87-94.

[26] P. Tétényi, T. Ollár, T. Szarvas, Sulfur exchange capacity and thiophene hydrodesulfurization activity of sulfided molybdena-alumina catalysts promoted by nickel, Catal. Today 181 (2011) 148-155.

[27] I. Bezverkhyy, S. Schneefeld, J. Skrzypski, J.P. Bellat, Reaction of thiophene with mono- and bimetallic $\mathrm{Ni}-\mathrm{Co}$ particles supported on gamma- $\mathrm{Al}_{2} \mathrm{O}_{3}$ and HDS activities of obtained sulfides, Appl. Catal. A: Gen. 371 (2009) 199-204.

[28] E. Rossetto, R. Beraldin, F.G. Penha, S.B.C. Pergher, Bentonites, Diatomites clays characterization and application in adsorption, Quim. Nova 32 (2009) 2064-2067.

[29] R. Gerber, Magnetic separation, in: Applied Magnetism, vol. 253, Erice, Italy, 1994, pp. 165-220.

[30] T.-C. Xiao, A.P.E. York, H. Al-Megren, C.V. Williams, H.-T. Wang, M.L.H. Green, Preparation and characterisation of bimetallic cobalt and molybdenum carbides, J. Catal. 202 (2001) 100-109. 